\title{
Mineração
}

\section{Regularização ambiental de minerações em Minas Gerais}

\author{
(Environmental regularization of mining activities in the \\ State of Minas Gerais, Brazil)
}

\section{Maurício Boratto Viana}

Geólogo e Bacharel em Direito pela UFMG, ex-Conselheiro do COPAM/ MG, Consultor Legislativo da Câmara dos Deputados, Mestre e Doutorando pelo Centro de Desenvolvimento

Sustentável da Universidade de Brasília (CDS/UnB)

E-mail: mauricio.boratto@camara.gov.br

\section{Maria Augusta Almeida} Bursztyn

Engenheira Civil e Ambiental, Professora do CDS/UnB, Doutora pela Universidade de Paris VI, França E-mail:dute@cds.unb.br

\section{Resumo}

Esse artigo tem por objeto de estudo a regularização ambiental de minerações em Minas Gerais, Estado onde tais atividades apresentam destacada importância econômica, social e ambiental. Descrevem-se as principais normas e resultados do licenciamento ambiental, bem como o pós-licenciamento, etapa em que o sistema fica, parcialmente, comprometido, em razão da insuficiente assessoria técnica às empresas de mineração e do assistemático acompanhamento das atividades impactantes pelo órgão ambiental. Também é feita uma avaliação preliminar das modificações introduzidas na gestão ambiental em Minas Gerais nos últimos cinco anos, incluindo a desconcentração ("regionalização”) do sistema de regularização - e da gestão ambiental como um todo -, com a criação de oito escritórios regionais e a instituição, em substituição ao licenciamento tradicional, da autorização ambiental de funcionamento, de natureza declaratória, para empreendimentos de menor porte e de menor potencial poluidor.

Palavras-chave: Regularização, licenciamento, pós-licenciamento, autorização, mineração, gestão, ambiental.

\section{Abstract}

This study deals with the environmental regularization of mining activities in the State of Minas Gerais, Brazil, where such activities exhibit prominent economic, social and environmental importance. The main environmental rules and data from the licensing system are analyzed, focusing on the post-licensing stage, when the system is partially hampered due to insufficient technical assessment and nonsystematic inspection of the impacting activities by the environmental authorities. A preliminary assessment of the changes introduced in the environmental system in the last five years is also made, and comprise: the regional decentralization of the licensing system - and of the environmental management as a whole -, with eight regional offices, and the institution of the declaratory authorization for environmental operation of minor enterprises with potentially less degrading activities, in substitution of the traditional licensing system.

Keywords: Regularization, licensing, post-licensing, authorization, mining activities, management, environmental. 


\section{Introdução}

A Lei 6.938/81, que dispôs sobre a Política Nacional do Meio Ambiente e instituiu o Sistema Nacional (Sisnama) e o Conselho Nacional do Meio Ambiente (Conama), deu poderes ao Conselho de fixar normas e critérios para licenciamento ambiental. Esse, como se sabe, é o procedimento (ou o processo) administrativo pelo qual o Poder Público, com objetivo preventivo (às vezes, corretivo), e desde que preenchidos pelo empreendedor os requisitos exigidos, licencia a localização, construção, instalação, ampliação e funcionamento de atividades e empreendimentos impactantes.

Mas a lei ambiental estipulou, como competente para o licenciamento, o órgão estadual, atribuindo ao federal competência supletiva e, depois, a de licenciar atividades com significativo impacto ambiental, de âmbito nacional ou regional. Por sua vez, o regulamento da Lei 6.938/81 fixou a necessidade de obtenção de três licenças: Prévia (LP), de Instalação (LI) e de Operação (LO).

Em 1986, o Conama editou a Resolução 001, que estipulou as atividades potencialmente causadoras de significativo impacto ambiental, entre as quais está a extração mineral, cujo licenciamento dependeria da elaboração de Estudo de Impacto Ambiental e respectivo Relatório (EIA/Rima). Em 1997, editou a Resolução 237, que fixou, não sem polêmica, a competência dos entes federativos, incluindo, dessa vez, os municípios, por força da autonomia que lhes foi conferida pela Constituição Federal de 1988.

Simultaneamente, os estados brasileiros passaram a elaborar legislação própria, gerando conflitos com as normas federais ou inovando e avançando em relação a elas (Câmara dos Deputados, 2007). Minas Gerais foi um dos estados pioneiros na implantação da legislação ambiental, com a Lei estadual 7.772/80, anterior mesmo à Lei federal 6.938/81. O Conselho Estadual de Política Ambiental (Copam, anterior Comissão), que precedeu ao Conama em quatro anos, destacou-se como o pri- meiro órgão colegiado no País a contar com a participação da sociedade civil, em representação paritária.

O órgão ambiental mineiro vem concedendo mais de mil licenças por ano, só para atividades industriais, minerárias e de infra-estrutura, que, até 2003, estavam sob a responsabilidade operacional da Fundação Estadual do Meio Ambiente (Feam). Até 2006, de todas as LPs emitidas, após a elaboração e análise de EIA/Rima, 78\% referiam-se a atividades minerárias (Ribeiro, 2006).

Excluídos os produtos energéticos, a produção mineral de Minas Gerais corresponde a quase $30 \%$ da nacional, empregando igual percentual de mãode-obra. Há uma boa variedade de bens minerais no subsolo mineiro, com destaque para minério de ferro, ouro, nióbio, fosfato, bauxita, calcário, quartzito etc. Além disso, 16 dos 27 maiores municípios mineradores do Brasil, além de quase metade das minas de grande porte, situam-se nesse Estado e quase metade da Compensação Financeira pela Exploração de Recursos Minerais (CFEM) arrecadada no País dele provém (DNPM, 2006).

Esses dados demonstram a importância da mineração no Estado. Por efeito, há diversas formas de exploração e beneficiamento dos minérios, que produzem impactos ambientais igualmente variados. Daí resulta a necessidade de um corpo técnico capacitado no âmbito dos órgãos de controle ambiental, das empresas de mineração e das consultorias que lhes prestam serviços.

Assim, há três décadas, Minas Gerais editou e pôs em prática legislação pioneira, dotada de mecanismos de transparência e participação social. Todavia, mesmo com todo esse pioneirismo e controle social, alguns setores específicos - ou partes deles - ainda não dispõem de suficiente adequação ambiental. No setor minerário, enquanto as grandes e médias empresas, regra geral, vêm cumprindo as normas ambientais há anos, as pequenas minerações e os garimpos permanecem com pouco ou nenhum controle ambiental.
A partir de 2003, o governo do Estado colocou em marcha uma reforma da administração pública. Na área ambiental, efetuaram-se alterações na legislação e no modelo de gestão, sendo a principal delas a desconcentração ("regionalização”) da Secretaria de Estado de Meio Ambiente e Desenvolvimento Sustentável (Semad) em, até agora, oito Superintendências Regionais de Meio Ambiente e Desenvolvimento Sustentável (Suprams), com sedes em cidades-pólo ${ }^{1}$, além da Superintendência da Região Central-Metropolitana.

Também passou a haver maior integração, até mesmo física, com a mudança, em 2007, para um mesmo prédio, na capital, dos órgãos seccionais responsáveis pelas Agendas Marrom (controle das atividades industriais, minerárias e de infra-estrutura), Azul (outorga do direito de uso dos recursos hídricos estaduais) e Verde (proposição e execução de políticas florestais, de pesca e aqüicultura e administração de unidades de conservação estaduais).

Outra modificação foi a introdução de uma nova modalidade de regularização, a autorização ambiental de funcionamento (AAF), de natureza declaratória, para atividades de menor porte e de menor potencial poluidor, que se sujeitam apenas ao cadastro, à apresentação de documentos de natureza formal e à assinatura de termo de responsabilidade. Assim, a regularização ambiental, em Minas Gerais, inclui, em síntese, a emissão, tanto de licenças, quanto de AAFs.

\footnotetext{
${ }^{1}$ São elas (entre parênteses, na ordem, o município-sede, a data de início de atividades e o ${ }^{\circ}$ de municípios abrangidos na Regional): Triângulo Mineiro (Uberlândia, Nov/2003, 67), Sul de Minas (Varginha, Dez/2003, 177), Alto São Francisco (Divinópolis, Mar/2004, 60), Zona da Mata (Ubá, Mar2004, 162), Norte de Minas (Montes Claros, Mar/2004, 91), Leste Mineiro (Governador Valadares, Abr/2004, 135), Jequitinhonha (Diamantina, Mai/2004, 56) e Noroeste de Minas (Unaí, Dez/2005, 21).
} 


\section{Material e Métodos}

Para a elaboração desse trabalho, efetuou-se um levantamento de dados em 2007, que incluiu: consultas a documentos junto ao órgão ambiental mineiro; visitas amostrais a 24 minerações (Tabela 1 e Figura 1) de sete bens minerais distintos (minério de ferro, ouro, calcário, quartzito, pedra-sabão, granito ornamental e filito), algumas detentoras de licença, outras de AAF e outras ainda clandestinas, para a verificação in loco da gestão ambiental e da adequação às normas e condicionantes do licenciamento; e entrevistas com 34 atores-chaves (metade dos quais ligada aos setores de apoio à mineração e metade ligada ao setor ambiental) e com os oito superintendentes regionais, acerca do sistema de regularização ambiental, em especial das atividades minerárias. ${ }^{2}$

\section{Resultados}

Embora as primeiras normas ambientais tenham sido elaboradas, em Minas Gerais, ainda no início da década de 1960, as específicas de controle e licenciamento datam de meados da década seguinte (FEAM/FJP, 1998). O marco inicial foi a criação da Comissão de Política Ambiental (Copam), transformada em Conselho dez anos após, que conferiu caráter pioneiro ao modelo do Estado, uma vez que os principais órgãos ambientais à época, a Companhia de Tecnologia de Saneamento Ambiental (CETESB/SP) e a Fundação Estadual de Engenharia do Meio Ambiente (Feema/RJ), não tinham colegiados com poder deliberativo e participação social tão ampla.

Em 1980, ainda antes do advento da Lei da Política Nacional do Meio Ambiente, foi editada a Lei Ambiental de Minas Gerais (7.772), ora em plena vigência. A criação da Fundação Estadual do Meio Ambiente (Feam) só ocorreria em 1987, ano em que foi aprovado o regulamento do Departamento de Recursos Hídricos (DRH), que só dez anos após seria transformado no Instituto Mineiro de Gestão das Águas (Igam) e incorporado, assim como o Instituto Estadual de Florestas (IEF), ao Sistema Estadual de Meio Ambiente (Sisema). Antes da regionalização, Feam, Igam e IEF eram os responsáveis operacionais pelas Agendas Marrom, Azul e Verde, respectivamente.

As normas mais importantes, quanto ao licenciamento, foram as deliberações normativas (DNs) que estabeleceram a classificação do porte e potencial poluidor de atividades degradadoras, entre as quais a DN 1/90, que vigorou durante 14 anos, até ser substituída pela DN 74/04. Esta prevê 22 tipologias para a mineração, em geral, com base na produção bruta, e fixa seis classes de enquadramento (1 e 2, passíveis de AAF, e 3 a 6, de licenciamento).

Quanto à fiscalização das atividades minerárias, até meados da atual década, ela era feita pelos técnicos da Feam responsáveis pelo licenciamento, com apoio do IEF e do Igam. Até então, o Grupo Coordenador da Fiscalização Ambiental Integrada (GCFai), criado, sem corpo técnico próprio, para o planejamento e a organização do controle e da fiscalização, durante uma década, teve atuação discreta, com exceção de ações emergenciais e operações especiais.

O GCFai, cujo nome foi mudado para CGFai (Comitê Gestor) em 2007, tem o apoio da Polícia Ambiental, formada, naquele ano, por 13 companhias especializadas em meio ambiente e trânsito, com cerca de 1.200 homens. A despeito do efetivo de cerca de 1.200 homens, distribuídos em 13 companhias especializadas em meio ambiente e trânsito, a maioria dos policiais não detém formação técnica e experiência necessárias para aferir o bom andamento das atividades minerárias. Em 2006, foi criada, na estrutura da Feam, a Diretoria de Monitoramento e Fiscalização Ambiental (Dirfim), com corpo técnico reduzido ${ }^{3}$.

Além disso, alguns controles do órgão ambiental simplesmente não funcionam. No caso do automonitoramento, por exemplo, salta aos olhos a inca- pacidade de pelo menos acompanhar, ainda que por amostragem, os dados periodicamente enviados pelas empresas de mineração. Os relatórios técnicofotográficos de cumprimento das condicionantes só são desarquivados, na maioria das vezes, pela superveniência de fato especial (acidente ambiental, denúncia da comunidade, solicitação do Ministério Público etc.).

Outra observação acerca do controle ambiental da mineração é a de que grande parte dos problemas decorre de um mau planejamento de lavra, como ocorre, frequentemente, com a lavra de minerais não-metálicos com menor valor agregado ${ }^{4}$. É certo que já houve importantes avanços no pós-licenciamento, entre os quais a introdução de prazos de renovação da LO, de quatro, seis ou oito anos, e a necessidade, vencidos estes, da elaboração do Relatório de Avaliação de Desempenho Ambiental (Rada). Todavia, tal relatório não vem funcionando como um instrumento de auditoria ambiental, como seria desejável.

\footnotetext{
${ }^{2}$ Para maiores detalhes: VIANA, Maurício Boratto. Licenciamento ambiental de minerações em Minas Gerais: novas abordagens de gestão (Dissertação de Mestrado). Brasília: Centro de Desenvolvimento Sustentável, Universidade de Brasília, 2007, 305 p. (site http://apache.camara.gov.br/portal/arquivos/ Camara/internet/publicacoes/estnottec/tesese-dissertacoes-1/Mauricio\%20Boratto.pdf).

${ }^{3}$ Naquele ano, foram fiscalizados $60 \mathrm{em}-$ preendimentos minerários ( $6 \%$ do total), incluindo detentores de licença e AAF e clandestinos (DIFISC, 2007). Comparandose com os dados de Ribeiro (2006), em que, das 850 LPs emitidas pelo Copam com EIA/ Rima até julho de 2006, 78\% referiam-se a minerações, observa-se que, se estas predominavam amplamente no processo de licenciamento, a elas não é dedicada a mesma atenção nas ações rotineiras de fiscalização.

${ }^{4}$ Em São Thomé das Letras, por exemplo, muitas vezes não há sequer levantamentos topográficos e geológicos das minas para indicar a localização dos corpos de minério. Com isso, pilhas de estéril são, às vezes, depositadas sobre eles, necessitando de posterior remobilização, com a perda dos serviços de implantação de vias de acesso, retaludamento, drenagem, revegetação etc.
} 
Tabela 1 - Minerações visitadas.

\begin{tabular}{|c|c|c|c|c|c|}
\hline Data & Mineração & Localização & Mineral & Título & Porte \\
\hline $14 / 03 / 2007$ & Capão Xavier (MBR) & $\begin{array}{l}\text { Bairro Jardim Canadá, Mun. } \\
\text { Nova Lima }\end{array}$ & Min. Ferro & LO & Grande \\
\hline $15 / 03 / 2007$ & Granasa - Granitos Nacionais & $\begin{array}{c}\text { Faz. Jaracatiá/Morro Alegre, } \\
\text { Mun. Ferros }\end{array}$ & Granito Orn. & AAF & Pequeno \\
\hline 02/04/2007 & Aglofilito Ind. Com. & Rodovia BR-381, Mun. Igarapé & Filito & LO & Pequeno \\
\hline 02/04/2007 & Pedra Azul/Domingos Ribeiro & $\begin{array}{c}\text { Estrada Catas Altas/Piranga, } \\
\text { Mun. Piranga }\end{array}$ & Pedra-sabão & Não & Pequeno \\
\hline \multirow{5}{*}{ 03/04/2007 } & Monte Verde Ltda. & Bacalhau, Mun. Piranga & Pedra-sabão & LOP & \\
\hline & Quality (ex-Verdita) & $\begin{array}{c}\text { Estrada Catas Altas/Piranga, } \\
\text { Mun. Piranga }\end{array}$ & Pedra-sabão & AAF & Pequeno \\
\hline & MSM Soapstone & $\begin{array}{c}\text { Estrada Catas Altas/Piranga, } \\
\text { Mun. Piranga }\end{array}$ & Pedra-sabão & Não & Pequeno \\
\hline & Monte Verde Ltda. & Pinheiros Altos, Mun. Piranga & Pedra-sabão & AAF & Médio \\
\hline & Extratil (Domingos) & Faz. Tabuão, Mun. Piranga & Pedra-sabão & LOP & Pequeno \\
\hline \multirow{3}{*}{ 04/04/2007 } & Monte Verde Ltda. & Faz. Quilombo, Mun. Piranga & Pedra-sabão & LOP & Pequeno \\
\hline & T. B. Loch & Faz. Chácara, Mun. Lamim & Pedra-sabão & AAF & Pequeno \\
\hline & Cava Brasil & $\begin{array}{l}\text { Distr. de Piedade, Mun. Ouro } \\
\text { Preto }\end{array}$ & Pedra-sabão & Não & Pequeno \\
\hline $12 / 04 / 2007$ & Córrego do Sítio (AngloGold) & $\begin{array}{c}\text { Faz. Cristina, Mun. Santa } \\
\text { Bárbara }\end{array}$ & Ouro & LO & Grande \\
\hline $13 / 04 / 2007$ & Pilar (MSOL) & Brumal, Mun. Santa Bárbara & Ouro & LO & Médio \\
\hline $16 / 04 / 2007$ & Ducal & $\begin{array}{c}\text { MG-439, km } 6 \text { - Sobradinho, } \\
\text { Mun. Pains }\end{array}$ & Calcário & TAC & Médio \\
\hline \multirow[t]{2}{*}{$17 / 04 / 2007$} & Serra do Corumbá (Imerys) & $\begin{array}{c}\text { Estr. Doresópolis-Pains, km } \\
\text { 18, Mun. Dor. }\end{array}$ & Calcário & LO & \\
\hline & 505 (Antônio Olímpio) & Capoeirão, Mun. Doresópolis & Calcário & TAC & Pequeno \\
\hline $19 / 04 / 2007$ & Esperança Starwood (Emesa) & $\begin{array}{c}\text { Serra dos Três Irmãos, Mun. } \\
\text { Brumadinho }\end{array}$ & Min. Ferro & AAF & Médio \\
\hline \multirow{3}{*}{ 24/04/2007 } & A. Pelúcio Com. Exp. Ltda. & $\begin{array}{c}\text { Serra São Thomé, Mun. São } \\
\text { Thomé das Letras }\end{array}$ & Quartzito & LO & Grande \\
\hline & Empr. Extr. Pedras São Tomé & $\begin{array}{c}\text { Serra São Thomé, Mun. São } \\
\text { Thomé das Letras }\end{array}$ & Quartzito & LO & Grande \\
\hline & $\begin{array}{l}\text { G. A. Pedras Brazil (arrendat. } \\
\text { Antônio Rocha) }\end{array}$ & $\begin{array}{c}\text { Serra São Thomé, Mun. São } \\
\text { Thomé das Letras }\end{array}$ & Quartzito & TAC & Médio \\
\hline $25 / 04 / 2007$ & Mineração Roma & $\begin{array}{c}\text { Serra São Thomé, Mun. São } \\
\text { Thomé das Letras }\end{array}$ & Quartzito & LO & Grande \\
\hline \multirow{2}{*}{ 09/05/2007 } & Minerita & $\begin{array}{c}\text { Serra Itatiaiuçu, Mun. Mateus } \\
\text { Leme/ltat. }\end{array}$ & Min. Ferro & LO & Médio \\
\hline & Minerminas (arrendat. Jafet) & $\begin{array}{c}\text { Serra Itatiaiuçu, Mun. } \\
\text { Igarapé/Itatiaiuçu }\end{array}$ & Min. Ferro & LO & Médio \\
\hline
\end{tabular}

Fonte: Levantamentos de Campo, março a maio de 2007.

Obs. Título Ambiental: LO = Licença de Operação; AAF = Autorização Ambiental de Funcionamento; Não = Mina Clandestina; LOP = Licença de Operação de Pesquisa (modalidade não mais existente; mina encerrada - reabilitada ou abandonada); TAC = Termo de Ajustamento de Conduta. 


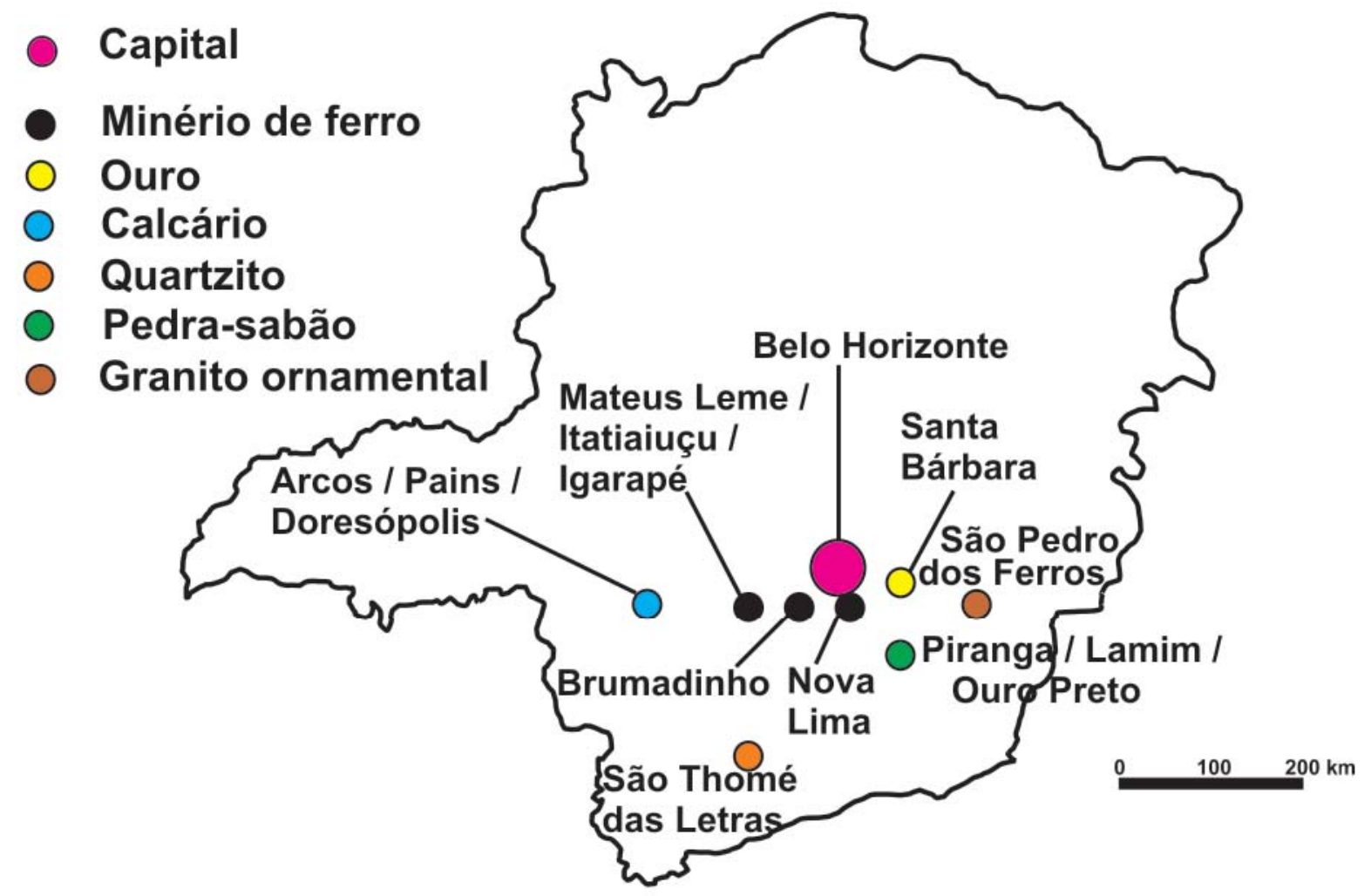

Figura 1 - Localização das minerações visitadas. Fonte da base: www.geominas.mg.gov.br/kit_desktop/kit2/imagens/mapas/basicos/mg.gif

A introdução da AAF, como um novo instrumento de regularização, trouxe complicadores. Se, por um lado, ela agiliza a regularização do empreendimento, por outro, na prática, ela exclui os estudos ambientais. $\mathrm{Na}$ ausência deles, o órgão ambiental corre o risco de autorizar empreendimentos, mesmo que de menor porte e de menor potencial poluidor, em locais e condições inadequados. Além disso, a AAF não permite o estabelecimento de condicionantes; com isso, perde-se um importante instrumento para resguardar, tanto o meio ambiente local, quanto os interesses das comunidades vizinhas aos empreendimentos.

A AAF tampouco se encaixa no procedimento fixado há anos pelo Departamento Nacional de Produção Mineral (DNPM) e a Feam para o licenciamento de minerações ${ }^{5}$. Ademais, os levantamentos mostraram que a AAF não vem promovendo avanço efetivo no controle ambiental de boa parte das minerações, embora retirando-as da clandestinidade ${ }^{6}$. Mesmo nos casos em que a empresa detém o título ambiental, a consultoria não a assessora na operação quotidiana, pautando sua atuação como mera "despachante ambiental”, apenas para "tirar a documentação".

Ainda com relação à AAF, metade dos entrevistados considerou-a um avanço, por ter reduzido a burocracia típica do processo de licenciamento ambiental, embora a grande maioria deles tenha enfatizado que esse avanço está intimamente associado à fiscalização, sem a qual o novo instrumento será completamente inócuo. Cerca de um quarto dos entrevistados pontuou que a AAF ajuda na regularização, mas não necessariamente no controle ambiental, enquanto que o outro quarto considerou que ela é um retrocesso no controle ambiental das atividades minerárias.
Os atores-chave foram unânimes quanto ao acerto da decisão de regionalizar o sistema ambiental, que poderia ser incrementado com o aumento e a qualificação do quadro de servidores e a valorização da carreira, bem como com o estímulo à adoção de sistema de gestão ambiental pelas empresas e à

\footnotetext{
${ }^{5}$ A situação chegou a tal ponto que, no início de 2007, a Procuradoria Geral do DNPM, em Brasília, não aceitava a AAF como documento hábil para a concessão da portaria de lavra. Interessante observar, também, que, na certidão da AAF, sequer constava o número do DNPM, o que dificultava, ainda mais, a associação dos títulos ambiental e mineral.

${ }^{6}$ Para ilustrar, basta o exemplo das extrações de pedra-sabão visitadas no Município de Piranga e arredores, localizadas próximas umas das outras, algumas clandestinas e outras detentoras de AAF, entre as quais não se detectou a menor diferença quanto à (má) qualidade ambiental durante as operações de lavra.
} 
criação de instrumentos econômicos. A maioria concordou que a regionalização estimula a regularização, um melhor controle ambiental e social, a participação da sociedade, a interiorização das diretrizes ambientais e a capacitação dos municípios, criando massa crítica no interior do Estado, embora aumente a influência de grupos de interesse (em especial, as prefeituras municipais) nas decisões dos conselhos.

Segundo as informações coletadas mediante entrevistas com os superintendentes regionais, há uma crescente relação de AAFs emitidas em comparação às licenças deferidas, com média três a cinco vezes superior, mas as vistorias, tanto no âmbito do pós-licenciamento, quanto dos processos de AAF, continuam bem inferiores às dos processos de licenciamento. Especificamente quanto às atividades minerárias, alguns superintendentes revelaram a ainda significativa clandestinidade de garimpos e pequenas minerações. Outra observação bastante comum foi quanto à fraca atuação do DNPM, ainda dissociada (com algumas exceções, como no caso das operações especiais do CGFai) da ação do órgão ambiental.

\section{Discussão}

As visitas efetuadas a algumas províncias minerais do Estado e as entrevistas com atores-chave mostraram que a qualidade das atividades poderia ser melhorada se houvesse acompanhamento técnico permanente pelo Poder Público, consultorias e entidades do setor mineral, uma vez que, em muitas das províncias, a exploração é feita por médias e pequenas empresas e, até, por garimpeiros.

Todavia, mais do que o porte e o potencial poluidor delas, ficou patente a existência de dois tipos de empreendedores: aqueles dignos desse nome, que envolvem significativa parcela de seus empregados nas questões ambientais e investem com seriedade nessa área, e os aventureiros, para os quais as normas ambientais e trabalhistas e as comunidades de entorno continuam sendo meros obstáculos para o desenvolvimento da atividade minerária.

Os empreendedores propriamente ditos têm faturamento razoável e não dependem só da atuação do órgão ambiental, pois suas ações são reguladas pelo mercado. Têm responsabilidade socioambiental e cuidam de sua imagem junto aos clientes, acionistas, financiadores e à própria sociedade. Executam suas atividades com segurança, cumprem condicionantes do licenciamento, preservam remanescentes de vegetação nativa, revegetam áreas degradadas, pagam as multas eventuais que lhe são aplicadas e promovem uma boa relação com seus empregados e as comunidades de entorno. É óbvio, contudo, que a pressão exercida por estas e a atuação sistemática dos órgãos fiscalizadores ajudam nesse bom desempenho. As minerações de minerais metálicos visitadas encaixam-se, em geral, nesse perfil.

Já os aventureiros apresentam menor faturamento, descumprem as condicionantes do licenciamento (isso, quando possuem licença) e as normas ambientais e trabalhistas (exceto as absolutamente necessárias), operam com certo risco, não preservam remanescentes de vegetação nativa nem revegetam áreas degradadas de forma significativa, desenvolvem poucas ações de educação ambiental junto aos funcionários e às comunidades de entorno, não pagam multas ou protelam o seu pagamento e acabam tendo de assinar Termos de Ajustamento de Conduta (TACs), que, em geral, tampouco são cumpridos. Mesmo que o órgão ambiental atue com firmeza, não há garantia de sua adequação. A maioria das minerações de minerais não metálicos visitadas enquadra-se nesse perfil.

São várias as razões da alta inadimplência socioambiental e trabalhista de mineradores desse tipo, que se somam à sua menor rentabilidade específica. Em primeiro lugar, por mais que des- cumpram as normas, eles, dificilmente, perderão o título minerário devido às hipóteses de caducidade da concessão de lavra previstas no art. 65 do Código de Mineração (Decreto Lei 227/67).

Em segundo lugar, tais mineradores também têm a quase certeza da complacência do Poder Público, pois é notório que a mineração em atividade ainda pode efetuar algum controle, mas, uma vez paralisada, torna a área um passivo ambiental de difícil reparação posterior, uma situação que é ruim para todas as partes. Exatamente por isso surgiu o instrumento do TAC, que muitos consideram um mal necessário, uma vez que permite a continuidade das atividades simultaneamente ao processo de regularização, mediante a promessa de adoção de uma série de medidas que, na maioria dos casos, permanece, infelizmente, como mera promessa.

Em terceiro lugar, sempre se alega que várias minas foram abertas ainda antes do advento da legislação ambiental, o que, de fato, é verídico. A verdade que se esconde é que a maioria dos problemas ambientais atuais advém de um mau planejamento de lavra, em desrespeito às condições estabelecidas no atual Código de Mineração - que incluem, por exemplo, a proibição da lavra ambiciosa -, muito do que já havia sido previsto no Código de Minas de 1940.

Por fim, é sempre alegado pelos mineradores que as oscilações do mercado e a falta de recursos suficientes impedem ou prejudicam a implantação das medidas de controle ambiental. Embora não se possa exigir o mesmo desempenho ambiental das empresas que exploram minérios de baixo valor agregado, os custos ambientais da mineração, na grande maioria dos casos, são bem inferiores aos demais. Além disso, desde o advento da legislação ambiental, eles devem ser incluídos no cálculo da viabilidade econômica da jazida. Assim, as que ainda não adotam tais medidas estão, no mínimo, praticando concorrência desleal em relação àquelas que as cumprem. 


\section{Conclusões}

Como visto, a emissão de AAFs pelas Suprams já vem superando, em muito, a concessão de licenças, mas a vistoria posterior a essa emissão quase não tem ocorrido. Contudo, se para o licenciamento e o pós-licenciamento a fiscalização é muito importante, no caso da AAF, ela o é ainda mais, dada a sua natureza declaratória. Admite-se que ela, por sua simplicidade procedimental em relação ao licenciamento, até possa vir a constituir um bom instrumento de regularização, mas esta só vai ultrapassar os limites da formalidade, caso o empreendimento seja, de fato, assistido pelas consultorias ambientais e fiscalizado pelo órgão ambiental.

Com a reestruturação do sistema ambiental mineiro a partir de 2003, cuja segunda etapa iniciou-se em 2007, o licenciamento e a AAF, em verdade, tornaram-se duas modalidades tão distintas de regularização ambiental que a opinião corrente entre os empreendedores minerários hoje, em Minas Gerais, é de que há empreendimentos sujeitos ao licenciamento ambiental, que "têm de fazer tudo”, e há os sujeitos à AAF, que “não têm de fazer nada”. É necessária, portanto, uma atuação mais firme do órgão ambiental no que tange à regularização ambiental por meio de AAF.
O fato é que, após três décadas da criação do Copam, o grande dilema das “minas gerais” de Minas Gerais permanece: se as médias e grandes mineradoras já estão, em sua maioria, ambientalmente adequadas, principalmente no caso dos minerais metálicos, como fazer com que garimpos e pequenas minerações, em especial as de minerais não-metálicos, incluindo agregados para a construção civil, também consigam alcançar um nível razoável de controle?

Não há uma resposta única para tal indagação. Todavia, a consideração de alguns problemas aqui abordados e a adoção de medidas para corrigi-los, tais como valorizar a equipe do órgão ambiental, concentrar esforços na extração de minerais explorados com maior descontrole e clandestinidade, assessorar os pequenos mineradores na adequação de suas atividades etc., certamente contribuiriam para vencer os desafios que ora ainda se apresentam.

\section{Referências \\ bibliográficas}

CÂMARA DOS DEPUTADOS. Seminário sobre legislação concorrente em meio ambiente. Câmara dos Deputados, 2007 (ver site www2.camara.gov.br/ publicacoes/estnottec/meioambiente/ index.html).
DEPARTAMENTO NACIONAL DA PRODUÇÃO MINERAL - DNPM. Anuário mineral brasileiro, 2006, ano base 2005 (ver site www.dnpm. gov.br/assets/galeriaDocumento/ AMB2006/I 2006.pdf).

DIVISÃO DE FISCALIZAÇÃO - DIFISC. Relatório de atividades de 2006. Difisc/ Dirfim/Feam, 2007 (relatório interno).

FUNDAÇÃO ESTADUAL DO MEIO AMBIENTE - FEAM \& FUNDAÇÃO JOÃO PINHEIRO - FJP. A questão ambiental em Minas Gerais: discurso e política. (org.: SANTA ROSA, Eleonora). Belo Horizonte: Semad/ Feam, FJP/Centro de Estudos Históricos e Culturais, 1998, 328 p.

RIBEIRO, José Cláudio Junqueira. Desafios do licenciamento ambiental. Belo Horizonte: Seminário estadual sobre licenciamento ambiental. Amda/Semad, 19/12/2006. 15 p. (ver site www.amda. org.br/assets/files/Palestra\%20Jose\%20 Claudio.pdf).

VIANA, Maurício Boratto. Licenciamento ambiental de minerações em Minas Gerais: novas abordagens de gestão . Brasília: Centro de Desenvolvimento Sustentável, Universidade de Brasília, 2007. 305 p. (Dissertação de Mestrado). (ver site http://apache.camara.gov. br/portal/arquivos/Camara/internet/ publicacoes/estnottec/teses-edissertacoes-1/Mauricio\%20Boratto. pdf).

Artigo recebido em 28/11/2008 e aprovado em 21/06/2009.

\title{
A REM tem novo endereço:
}

\author{
FUNDAÇÃO GORCEIX - REM \\ Rua Carlos Walter Marinho Campos, 57 \\ Bairro: Vila Itacolomy \\ 35400-000 - Ouro Preto - MG \\ $\begin{array}{ll}\text { (31) } 3551-4730 & \text { (31) 3559-7408 }\end{array}$
}

www.rem.com.br 